\title{
Steering Clear of driving after drinking: a tailored e-health intervention for reducing repeat offending and modifying alcohol use in a high risk cohort
}

Hollie Wilson, Gavan Palk, Mary Sheehan, Darren Wishart, Barry Watson.

\section{Abstract}

Purpose: Digital interventions to reduce risk behaviours are emerging as effective public health measures; however, few have been applied to drink driving and associated alcohol use based on a harm reduction perspective. This paper reports on the design, development, and pilot of a novel intervention which aims to reduce repeat offending by first time convicted drink driving offenders. It explores whether an online program is acceptable and user friendly, and contains useful and relevant content, with a sample of first time drink driving offenders recruited at the time of conviction.

Methods: Building upon existing research into interventions to reduce drink driving recidivism and problem alcohol use, a tailored program was designed to provide content specifically concerned with drink driving and with an additional component related to alcohol use. Following stakeholder and internal review, the 'Steering Clear First Offender Drink Driving Program' was subsequently piloted with 15 first time drink driving offenders. Evaluative data was analysed both quantitatively and qualitatively.

Results: The pilot results indicate that the participants found the program to be user friendly, as demonstrated by high scores in relation to navigation, online delivery, engagement, avatar usage, and straightforwardness. They reported that they found the content to be useful and relevant and that the key learning area was in relation to the consequences of drink driving.

Conclusions: Online interventions for reducing risky behaviour such as drink driving may be useful and cost effective from a public health perspective. Potentially, they can directly address risky behaviours associated with alcohol use in high risk cohorts that may not ordinarily receive intervention.

Keywords: online intervention; drink driving; health risk behaviour; Steering Clear First Offender Drink Driving Program; alcohol; treatment. 
There is a clear relationship between a person's Blood Alcohol Content (BAC) and their crash risk. The risk becomes higher at a $\mathrm{BAC}$ of $0.05 \mathrm{~g} / 100 \mathrm{ml}$, with the crash risk of a driver at $0.10 \mathrm{~g} / 100 \mathrm{ml}$ being almost five times the risk of a driver with no alcohol in their system, and with $0.15 \mathrm{~g} / 100 \mathrm{ml}$ being 22 times higher [1]. The reported incidence and prevalence of drink driving varies across countries and is dependent on enforcement methods and intensity and legal BAC levels [2]. The numbers of alcohol associated road fatalities also vary for similar reasons. In Australia around 1 in 5 drivers and riders killed on Australian roads have a BAC over the legal limit for their licence level [3]. The present intervention was designed in the context of state legislation involving enforcement by random breath testing for a BAC of 0.05 or higher. A study in 2010 indicated an offence rate of approximately 1:85 tests in a tested sample of 3.3 million breath tests per annum [4]. Of these, $73.1 \%$ were first offenders or first time convicted within a five year period. A key target group for prevention would be those persons who present to court for the first time with a drink driving offence. There are no clear indicators as to how to select those offenders who will go on to re-offend from this group and this program was designed to be a simple, accessible health promotion intervention that could be used as a sentencing option.

\section{E-interventions for reducing risky behaviour}

Nearly half (42.4\%) of the world population uses the internet, with a substantial proportion of the population in Europe (70.4\%), North America (86.9\%) and the Oceania region $(72.1 \%)$ having internet access [5]. Smartphones are owned by $89 \%$ of Australian adults [6] who spend an average of 29 hours per month using apps [7].

With this level of use there has been an associated international growth in research and development of digital interventions to reduce risky behaviour. The number of mHealth apps published on iOS and Android platforms has been estimated as more than 165,000 mHealth apps (free and paid) publicly available. However, the effectiveness of health apps in many areas remains largely untested and unknown [8].

E-interventions or computer based health interventions aim to provide readily available and self-directed interventions for persons with easy access and confidence using computer programs. They have been used to disseminate brief interventions, motivational techniques, education and tailored messaging [9]. They have the potential to enable information and screening programs to be available to people living in rural and remote communities with limited access to treatment services. The content, structure and goals of e-interventions vary, but materials sent by the internet can be interactive and give the participant individual experience that could be of particular relevance for problem screening.

On-line interventions addressing harmful substance use [10-12] have received considerable research interest and have been demonstrated in meta-analytic studies to be efficacious. For example, there has been considerable development of interventions to reduce problematic alcohol use in adult populations. Some of these have shown a demonstrated effect for up to 6 or 9 months post treatment, with more extended interventions providing an even greater effect than single session or normative feedback interventions $[11,12]$. This 
extended treatment effect has also been demonstrated for reduction of tobacco use [10]. The most effective health behaviour change programs are theory based and incorporate one or more behaviour change techniques, and the effectiveness of such programs is enhanced by additional personal contact with participants [13].

There have been a few applications of digital technologies in screening of DWI offenders in the United States, particularly as a mechanism for determining relevant treatment pathways such as face-to-face therapy for substance use by offenders prior to court appearance. A study reported by Mullen et al. [14] recruited DWI offenders through a court in order to target an intervention to persons with demonstrated problem drinking. The court appearance was considered to be an index of need for treatment and opportunity for measuring the effectiveness of self-assessment by computer assisted alcohol related screening. A Californian trial [15] used web-based motivational interviewing as an addition to a conventional class room based drink driving program and again focussed on skills for reducing drinking. It proposed that future interventions should take into account the potential level of alcohol dependency in DUI samples and integrate cognitive behavioural therapy strategies as a more intensive intervention. The present intervention is innovative because it acknowledges that while alcohol treatment may be effective in reducing levels of drinking this may not necessarily reduce such drinking to the legal levels required for safe driving. It therefore targets drink driving explicitly by combining skills and knowledge to assist with safe driving by separating drinking from driving and also includes screening and drink tracking features to reduce or manage behaviours. The 'Steering Clear' program (www.steeringclear.com.au) incorporates both motivational strategies, as well as CBT strategies in a tailored format, so the user is provided with relevant techniques to increase their level of motivation to change their drink driving behaviour as well as further screening and tasks to enable insight into personal levels of alcohol consumption. The design of both components of the intervention is based on operationalising the theoretical model of the Health Action Process Approach (HAPA) [16]. Specifically, it includes sections on plan building to change and strategies to maintain self-efficacy as well as action and coping plans to avoid future drink driving.

There is modest support for the efficacy of self-help materials $[9,17,18]$ for reducing alcohol use. If this effect is also found for the computer delivery of a drink driving intervention for first offenders in Australian conditions it could be particularly beneficial. It would be cost effective compared to face to face interventions with associated professional salary costs and it could facilitate access to treatment for those living in rural and remote locations. In such circumstances it could provide a sentencing option that is realistic for magistrates in non-urban courts. Another potential benefit lies in the finding that alcohol consumption benefits have been found in those who did not seek treatment [19], including in cases of mandated participation [17]. However, the magnitude of effect is less in those not seeking treatment [19].

\section{Brief alcohol interventions}

It is established that as an initial step, screening for problematic alcohol consumption and providing feedback and a brief intervention can be effective methods to provide information 
about alcohol effects and healthy levels of consumption [20-24]. The aggregate evidence of systematic reviews ( 24 systematic reviews covering a total of 56 randomized controlled trials reported across 80 papers) indicates that a brief intervention is effective for addressing hazardous and harmful drinking in different cultural settings and across age groups [25]. Brief interventions seem to be most effective for mild to moderate alcohol problems [26]. The optimal duration and content of the brief intervention requires more investigation but generally screening via the Alcohol Use Disorders Identification Test (AUDIT) [27] is undertaken followed by structured advice and, if necessary, motivational interviewing across 1 or 2 brief sessions $[23,28]$. If the initial screening identifies alcohol dependence referral for intensive treatment is recommended.

The 'Steering Clear' program is a five module (two hours) tailored intervention delivered online. It is theory based, provides important information related to driving and drinking and aims to maximise personal involvement and relevance by being avatar guided and highly interactive. The aim of the program is to allow first offenders to become aware of their own drink driving and associated alcohol related behaviour in order to prevent reoffending. The program can be used via the internet at home, mobile phone or tablet and it is designed to target first time convicted drink drivers with breath analysis content under $0.15 \mathrm{~g} / 100 \mathrm{~mL}$.

The content presentation provides key information required to understand impairment to driving at different levels of BAC, metabolism of alcohol, and the calculation of "standard drinks" and associated BAC levels which is a core component of drink driving education and management in Australia. These modules are followed by planning and action modules related to drink driving that are based on action planning, coping planning, relapse prevention strategies and maintenance self-efficacy drawn from the HAPA [16]. The second phase of the intervention draws on the brief intervention model for the management of drinking and uses Motivational Interviewing premises of the Transtheoretical Model [28]. A summary of the intervention content and the strategies used to gain the participants' active involvement in the change process is given in Table 1.

Table 1. Intervention Content

\begin{tabular}{|l|l|}
\hline Key constructs & Intervention strategies \\
\hline Drink Driving risk perception & $\begin{array}{l}\text { Education: presentation of data on alcohol } \\
\text { associated crash fatalities }\end{array}$ \\
\hline $\begin{array}{l}\text { Lack of knowledge (standard drinks, effects } \\
\text { of alcohol, BAC levels) }\end{array}$ & $\begin{array}{l}\text { Education; rehearsal, quizzes (recall of } \\
\text { information) }\end{array}$ \\
\hline $\begin{array}{l}\text { Consequences (personal, legal, societal, } \\
\text { family) }\end{array}$ & Behavioural discrepancies; social support \\
\hline Decision making & $\begin{array}{l}\text { Challenging decisions to drink drive (MI } \\
\text { based) [28], goal setting }\end{array}$ \\
\hline Building plans and self-efficacy to plan & $\begin{array}{l}\text { Plan building (HAPA based) [16]; problem } \\
\text { solving; confidence exercises }\end{array}$ \\
\hline Self-efficacy to avoid drink driving & $\begin{array}{l}\text { Mastery, action planning (HAPA based) [16], } \\
\text { vicarious learning (extended deterrence) }\end{array}$ \\
\hline Risky substance use / alcohol & $\begin{array}{l}\text { Screening; AUDIT [27]; brief intervention; } \\
\text { self-monitoring/tracking; education on risks, }\end{array}$ \\
\hline
\end{tabular}




\section{Goal and aims}

The present study is a process evaluation to determine the applicability of the intervention to the target group. It aims to determine whether the program will be used by the offender group and whether the content and design are user friendly. The study explicitly examined navigation, online delivery; engagement and use of an avatar; straightforwardness and usability.

\section{Methodology}

\section{Step 1: Design, content and engagement}

There were a number of steps and activities incorporated within the design of the Steering Clear platform and program content to assist participant engagement and interest to encourage ongoing use. Within the context of online behaviour change interventions, previous research has highlighted the importance of the concept of engagement, particularly in relation to the quality of user experience, sensory intellectual satisfaction, attentional increase and positive effect [29]. In addition, research has found that engagement is a crucial consideration for online interventions to enable participants to obtain the full benefits of a program by specifically aiming to increase the likelihood of participants adhering to the intervention for as long as possible [30]. In order to address these challenges, during the development process the research team not only referred to previous research but also utilised the services and expertise of a Brisbane based consulting firm experienced in the development of information technology and internet based platforms.

\section{Functionality}

On their first visit to the website participants are greeted with an introduction that outlines the program. This is followed by information guiding them through the workings of the system. Participants are instructed to register and provide some demographic information such as first and last names, an email address and password. Participants then receive a verification notification to their supplied email address requesting them to log in using the password they provided if they wish to complete the program. They receive information regarding requirements for completion of the program and are encouraged to select an avatar.

\section{Avatars}

An avatar is the user's on-screen persona, and has been described as the 'user embodiment' in a virtual environment [31] with various actions such as walk, run, wave and jump that the user can control using the keyboard and mouse [32]. The use of avatars helps enable direct visual interaction with the 3-D environment and with other avatars in the virtual world. 
Previous research has shown that the use of avatars can be a powerful tool to enhance the learning and motivation of students [33]. Prior to commencing the program each participant is prompted to make a choice from a range of avatars to assist them in the learning outcomes and provide guidance and audio assistance with instructions throughout the completion of the program.

\section{Videos, Animation \& Images}

In order to enhance the presentation of information for participants and improve learning outcomes, the Steering Clear program modules included a range of video scenarios, animation and presentation of images. For example, in the module educating participants about the effects of alcohol on the body, information was conveyed by an animated representation of a person and the journey undertaken by alcohol through the body and various depictions of internal organs and processes. The animation is also accompanied by an audio explanation of the process and effects on bodily function to aid in communicating information. To further assist participant learning styles the audio transcript is provided to read.

\section{Information Quality}

At the beginning of each topic the avatar chosen by the participant provides an overview of the content of the topic. The Steering Clear program consists of a range of topics which include various related knowledge-based tests for participants to complete after viewing the information presented regarding the effects of alcohol on driving. All contents of the program were developed using an iterative process involving ongoing review and advice from an expert internal panel. (See appendix 1.)

Each set of questions presented relates to content presented within the module with answers provided in a multiple-choice format. In addition to multiple choice questions, modules also contain various interactive activities designed to encourage participants to engage in learning activities. For example, participants are able to choose the typical type of drink they normally consume along with options of size and alcoholic strength of the chosen drink. They are then presented with a range of options to indicate the size of a standard drink and provided feedback on the difference and contribution to personal BAC. In the event of participants being incorrect they are provided with accurate information as to how many standard drinks their choice was along with an activity to assist in calculating standard drinks correctly.

\section{Drink tracker web app}

A drink tracker was included in the 'Steering Clear Program' designed to estimate the potential therapeutic effectiveness of the program. The drink tracker is a hybrid web app, and on completion of 'Steering Clear' is automatically updated with relevant tailored information from the program such as the user's plan to avoid drink driving. 
Given sensitivities of data and privacy concerns associated with participants engaging in the 'Steering Clear Program', the data management system development used two separate data storage locations. This approach meant that both data sets are in conformity with Australian NHMRC ethical requirements for human behaviour research [34]. The first database, the 'Steering Clear' internal database consisted of the storage of information relating to initial identifying demographic information relating to participants. For example, demographic details included participant first name, gender, a password to obtain 'Steering Clear' participant access and informed consent. Other uniquely identifying information obtained through participant registration processes such as last name, date of birth, and address were exported for un-linked storage on an external database. The storage of these various components of participant information across two different databases was undertaken to protect privacy in the event of a potential breach of security through hacking. In regards to the data exported to the external database, the system exported the data in regular timed batches and once completed the data exported is automatically removed from the system database. However, to assist in the future research and evaluation of the 'Steering Clear Program', researchers could match the data retrieved from both databases using unique coding identifiers and with participants' consent.

\section{Step 3: Piloting}

For Phase 1 of the pilot, the prototype of the program was initially tested with an internal sample of eight road safety researchers, two Government (transport) representatives (to ensure quality control), and an e-learning consultant to test both the online mechanism and the content and ensure its presentation and design were suitable for the target audience. For Phase 2 of the pilot, the revised program was delivered to a sample of 15 first time convicted drink driving offenders in two Magistrates Courts (metropolitan and regional). Offenders had BAC levels of under $0.15 \mathrm{~g} / 100 \mathrm{ml}$ which was a requirement for the study due to the tailored content. The sample were recruited immediately after sentencing in the courthouse and asked to complete the program at a later time on a computer or mobile device. The pilot was approved by the QUT research ethics committee.

A questionnaire was integrated into a final (evaluation) module. The questions pertained to the program itself (for example, usability, online delivery of content, and navigation) and the content of the program (including the value of the information and personal relevance). The questionnaire consisted of slider items (scale 1-100), true/false questions, and open text boxes to measure qualitative responses. Some items were questioned in the reverse form e.g. 'I found the program not very straightforward to work through'.

Results 
Participants were recruited at the Cairns and Brisbane Magistrates courts following the court hearing for their first offence. Only those with a low range offence $(<0.15 B A C)$ were recruited as that is the target population for the intervention. They were approached in the foyer and asked if they would like to participate in the project. Participants were provided with a nominal reimbursement ( $\$ 50$ voucher) to complete the program trial.

\section{Demographics}

Of the 15 offenders who participated in the pilot, 10 were male, and 5 were female. The average age was 30 years.

\section{Program statistics}

The average number of sessions to complete the program was $2.03(S D=1.22)$. The largest proportion of the sample completed the program over one session $(n=6,40 \%)$, with smaller numbers of offenders completing the program over two sessions ( $n=5,33.3 \%$ ), three sessions ( $n=2,13.3 \%)$, four sessions ( $n=1,6.7 \%)$ and five sessions ( $n=1,6.7 \%)$. Of the sample, the majority used only a computer $(n=10,66.7 \%)$, some used both computer and mobile phone equally over the sessions ( $n=4,26.7 \%)$, and one used a mobile phone for three quarters of the sessions and a computer for one quarter $(n=1,6.7 \%)$. No participants in the pilot used a tablet device to complete the program. The time taken to complete the program was recorded by the program. The majority of participants completed it in 1-1.5 hours ( $n=8,53.3 \%)$, with smaller numbers of participants completing in 2 hours $(n=3$, $20.0 \%)$, less than one hour $(n=2,13.3 \%)$, and three or more hours $(n=2,13.3 \%)$.

\section{Questionnaire data}

\section{Program items}

A number of program questions were asked in a true/false format. In terms of navigation, the majority of participants responded that the pages were easy $(n=14,93.3 \%)$. In terms of the online delivery, the majority of participants responded that they would prefer online intervention than face-to-face ( $n=14,93.3 \%)$. In terms of engagement, the majority found the program to be visually engaging ( $n=14,93.3 \%$ ). In terms of the avatar, the majority found the guidance through the program to be useful $(n=13,86.7 \%)$. In terms of straightforwardness, the majority of the sample indicated that the program was straightforward ( $n=13,86.7 \%$ ). Overall usability of the program, measured on a 1-100 scale of not useful at all - very useful, was high $(M=90.80, S D=20.97)$.

\section{Content items}

Participants were asked whether the program made them think about not drink driving in the future and whether the program made them think about changing their drinking and there was $100 \%$ agreement $(\mathrm{N}=15)$ on both items. It is accepted that information is required for health behavior change and that "health communication programs and 
materials that succeed in making information relevant to their intended audience will be more effective than those that do not" [35]. Participants were asked on a 1-100 point sliding scale whether the information in each module was valuable and personally relevant. The results of this question as well as paired t-tests to demonstrate the differences between information and relevance scores are as per Table 2, below.

Table 2. Information value and content relevance to first offenders ( $N=15$ )

\begin{tabular}{|l|l|l|l|}
\hline & Information & Relevance & Sig. Difference \\
\hline $\begin{array}{l}\text { Module 1: Standard } \\
\text { drinks }\end{array}$ & $\mathrm{M}=90.67, \mathrm{SD}=17.05$ & $\mathrm{M}=81.40, \mathrm{SD}=28.24$ & $t(14)=.433, \mathrm{p}=.67$ \\
\hline $\begin{array}{l}\text { Module 2: Alcohol } \\
\text { and the body }\end{array}$ & $\mathrm{M}=94.07, \mathrm{SD}=14.26$ & $\mathrm{M}=88.13, \mathrm{SD}=18.51$ & $t(14)=3.27, \mathrm{p}=.006$ \\
\hline $\begin{array}{l}\text { Module 3: } \\
\begin{array}{l}\text { Consequences of } \\
\text { drink driving }\end{array}\end{array}$ & $\mathrm{M}=85.27, \mathrm{SD}=21.46$ & $\mathrm{M}=73.87, \mathrm{SD}=24.51$ & $t(14)=2.16, \mathrm{p}=.049$ \\
\hline $\begin{array}{l}\text { Module 4: Planning } \\
\text { ahead }\end{array}$ & $\mathrm{M}=78.00, \mathrm{SD}=21.87$ & $\mathrm{M}=70.40, \mathrm{SD}=25.11$ & $t(14)=1.85, \mathrm{p}=.09$ \\
\hline $\begin{array}{l}\text { Module 5: Your } \\
\text { alcohol use }\end{array}$ & $\mathrm{M}=79.27, \mathrm{SD}=33.15$ & $\mathrm{M}=81.33, \mathrm{SD}=25.65$ & $t(14)=-0.417, \mathrm{p}=.68$ \\
\hline
\end{tabular}

All scores were high however with the exception of "Your alcohol use" the value of the information was rated more highly than its personal relevance. In the modules "Alcohol and the body" and "Consequences of drink driving" the differences were significant. Two motion graphics videos were also created for the program, to be integrated into Modules 1 and 2 of the program. These are 3-4 minute videos relating to standard drink measurement (video 1), and the effects of alcohol metabolism on the body (video 2). On the sliding scale relating to usefulness, both videos were rated highly (Video $1 M=80.93, S D=25.13$; Video 2 $M=82.40, S D=23.89$ ).

Participants were asked to identify the three most important things they had learned from the program. Their comments were entered as text data into boxes on the screen. These comments were then classified according to the module theme they addressed, e.g. the comment "I learned that I shouldn't use a glass as a measure for a standard drink of alcohol" was classified as referring to Module 1 (standard drinks). There were 42 responses in all and these included 5 responses that couldn't be classified into any one of the modules but provided an overall indication of material learned, e.g., "don't drink and drive", and "education leads to better decision making". One participant did not provide any responses. The numbers of comments on each module are provided in Table 3. Where a participant noted two key learning points from the same module, they were both counted for the same module.

Table 3. Key learning areas of the Steering Clear First Offender Drink Driving Program for the drink driver participants $(n=14)$

\begin{tabular}{|l|c|l|}
\hline & Count & Examples \\
\hline $\begin{array}{l}\text { Module 1: } \\
\text { Standard drinks }\end{array}$ & 7 & $\begin{array}{l}\text { 'This is fantastic - it really is hard to get accurate information on } \\
\text { how many drinks is a standard drink ...' } \\
\text { 'How to calculate a standard drink' }\end{array}$ \\
\hline
\end{tabular}




\begin{tabular}{|l|c|l|}
\hline $\begin{array}{l}\text { Module 2: } \\
\text { Alcohol and the } \\
\text { body }\end{array}$ & 8 & $\begin{array}{l}\text { 'That alcohol can stay in the system much longer than I thought' } \\
\text { 'That greasy food, coffee, vomiting, did not sober you up and that } \\
\text { the liver can only process one standard drink an hour' }\end{array}$ \\
\hline $\begin{array}{l}\text { Module 3: } \\
\text { Consequences } \\
\text { of drink driving }\end{array}$ & 11 & $\begin{array}{l}\text { 'Realising the consequences on me and also those around me } \\
\text { including strangers that I could be endangering' } \\
\text { 'The possibility of wrecking not only your own life and families life } \\
\text { but the possibility of ruining some other persons' }\end{array}$ \\
\hline $\begin{array}{l}\text { Module 4: } \\
\text { Planning ahead }\end{array}$ & 7 & $\begin{array}{l}\text { 'Plan ahead to avoid the short sighted decisions made when drunk' } \\
\text { 'Thinking about my 'go to' plans for the times when I have drunk and } \\
\text { need to get home without driving' }\end{array}$ \\
\hline $\begin{array}{l}\text { Module 5: Your } \\
\text { alcohol use }\end{array}$ & 4 & $\begin{array}{l}\text { 'Personal alcohol consumption and the health effects by drinking too } \\
\text { much alcohol' } \\
\text { 'That the alcohol content in my chosen drink is much higher than I } \\
\text { thought' }\end{array}$ \\
\hline
\end{tabular}

The counts of the associated comments and examples are given and the "consequences" were most frequently noted and "personal alcohol consumptions" least frequently.

\section{Drink tracker app usage and comments}

The participants were not required to access the attached web app designed for ongoing alcohol tracking as part of the current evaluation, but all participants opted to do so and logged on to the tracker. When asked whether they would use the tracker to help stop them drink driving, 7 participants (46.7\%) indicated that they would. When asked whether they would use the tracker to help them control their alcohol use, 10 participants $(66.7 \%)$ indicated that they would do so.

\section{Discussion}

Despite the serious nature and consequences of alcohol impaired driving, it continues to be a major contributor to fatalities and injuries caused by road crashes. For the most part, intervention programs are aimed at the reduction of subsequent drink driving by 'hard core' that is high BAC repeat offenders, with licence disqualifications and financial penalties being applied to first offenders. From an economic standpoint, e-health interventions to reduce such risk behaviour at an early stage could have widespread benefit.

While the core aim of the present program is to encourage separation of driving from drinking, tailored therapeutic activities related to alcohol use reduction or cessation are included and were deemed to be relevant. All participants reported that the program made them think about changing their drinking, as well as making them think about not drink driving in the future. This finding is an important one, as the majority of first offenders are high risk alcohol users and up to a third of first offenders self-report drink driving again within the six months following a first-time conviction [36]. The finding that the majority of offenders taking part would also continue to use the drink tracker web app was surprising as this is an optional add-on tool to the core program. This indicates that an app (native or hybrid) may be an important digital component of drink driving programs. 
Offenders rated two of the modules, 'alcohol and the body' and 'consequences of drink driving', as having high information quality but significantly less personal relevance. The selfreported key learning areas, however, provided support for the importance of both of these modules, which were mentioned the most in the qualitative reports on what the offenders had learned from the program. This may indicate that there is scope to improve these modules in particular to make them more personally relevant and tailored to individual circumstances. It may also indicate that knowledge and consideration of consequences by offenders was already high in the offender group following detection.

The developed program is novel and offers a number of strengths including a strong theoretical base. The program provides the opportunity for convicted drink drivers to assess their level of risky alcohol consumption and provision of referral for more intensive treatment. There are, however, a number of limitations to be considered. The recruitment rate was lower, less than half of those approached agreed to participate than that of other research projects with similar offender samples (over 50\%), which may demonstrate a selfselection bias. As a result of this pilot, the next wave of potential candidates should be those who have been charged but have not as yet attended court. This would present a value proposition to offenders (who could then demonstrate upon court attendance they have undertaken intervention). The study was a pilot, and as such lacks ecological validity. When the program is implemented on a wider scale, reimbursements will not be offered and the program will be further tailored to suit first offenders who have not yet attended court. Further, the digital literacy of the sample was not assessed during recruitment, so it is possible that those who declined participation may have not been confident in accessing a computer or completing the program in the online format.

While offenders reported that the program was useful and made them consider avoiding drink driving, it was a process evaluation and it is unknown whether it will be effective in reducing drink driving or other traffic offending behaviour in either the short or long term. This should be the focus of the next stage of the research and involve official transport data and follow up by self-report on driving and consumptions outcomes.

\section{Conclusion and future directions}

The Steering Clear First Offender Drink Driving Program is a novel tailored online intervention that could be implemented on a large scale to reduce offences relating to driving and alcohol and to address alcohol use in a high risk cohort that does not consistently receive intervention. Importantly, this pilot indicates that online interventions are dynamic and can enable rapid translation of research into evidence-based practice and provide individually tailored relevant behaviour change strategies.

The pilot study demonstrated that the online program is technologically robust, and there were minimal difficulties in progression through the program modules. Usability and designs were rated as extremely good, which indicates that the program design suits the target group. Future directions include the option to tailor the program as an adjunctive tool to suit other offender groups, such as repeat offenders or those requiring an alcohol ignition interlock. Investigations into suitable programs to reduce other drug driving should be 
considered. The program should be studied longitudinally and on a larger scale to determine whether the current results are replicated. Digital technologies offer a cost-effective public health intervention, and their expansion into the field of traffic safety has significant potential for widespread benefit. 
Appendix 1: Background research and theoretical basis for program activities

\begin{tabular}{|c|c|c|}
\hline Module & Basis & $\begin{array}{l}\text { Behaviour change } \\
\text { mechanisms }\end{array}$ \\
\hline $\begin{array}{l}\text { Module 1: } \\
\text { Standard } \\
\text { drinks }\end{array}$ & $\begin{array}{l}\text { There is general confusion among community and } \\
\text { offender groups as to what actually constitutes a } \\
\text { standard drink. This is particularly relevant to the } \\
\text { Australian context where this assumed knowledge is } \\
\text { widely available. Thus, the module provides } \\
\text { engaging sources of information as psychoeducation. }\end{array}$ & $\begin{array}{l}\text { Demonstration of } \\
\text { behaviour (pouring } \\
\text { drinks). } \\
\text { Education on health } \\
\text { measures and levels } \\
\text { of risky use. }\end{array}$ \\
\hline $\begin{array}{l}\text { Module 2: } \\
\text { Alcohol and } \\
\text { your body }\end{array}$ & $\begin{array}{l}\text { Drink driving offenders often lack knowledge on the } \\
\text { effects of alcohol and the body, and how long it } \\
\text { takes to metabolise alcohol (e.g. when they will be } \\
\text { under the legal limit to drive the morning after a big } \\
\text { night of drinking). There is also a lack of knowledge } \\
\text { on the concepts of reaction time and stopping } \\
\text { distance. This module educates the user on the } \\
\text { effects of alcohol and how they impact the driving } \\
\text { task, with a focus on the separation of drinking from } \\
\text { driving. }\end{array}$ & $\begin{array}{l}\text { Provision of } \\
\text { feedback on } \\
\text { performance. } \\
\text { Feedback and } \\
\text { education on risks } \\
\text { (e.g. stopping } \\
\text { distance under } \\
\text { different BAC } \\
\text { levels). } \\
\text { Normative data } \\
\text { comparison. }\end{array}$ \\
\hline $\begin{array}{l}\text { Module 3: } \\
\text { Consequences } \\
\text { of drink } \\
\text { driving }\end{array}$ & $\begin{array}{l}\text { Often drink driving decisions are made without } \\
\text { consideration of the significant and real } \\
\text { consequences of engaging in the behaviour. Often, } \\
\text { offenders are not aware of the array of } \\
\text { consequences of being convicted of an offence (e.g. } \\
\text { legal, financial), as well as the potential } \\
\text { consequences to others (e.g. having to rely on others } \\
\text { for transportation). This module emphasises the } \\
\text { consequences of drink driving and the most relevant } \\
\text { individual consequences for consideration by the } \\
\text { user. }\end{array}$ & $\begin{array}{l}\text { Provision of } \\
\text { information on } \\
\text { consequences in } \\
\text { general (e.g. legal, } \\
\text { personal, to } \\
\text { others), as well as } \\
\text { personalised } \\
\text { feedback on } \\
\text { consequences for } \\
\text { the individual. }\end{array}$ \\
\hline $\begin{array}{l}\text { Module 4: } \\
\text { Planning } \\
\text { ahead }\end{array}$ & $\begin{array}{l}\text { Planning has been demonstrated to be an important } \\
\text { component of reducing repeat offending by drink } \\
\text { drivers. } \\
\text { This module was largely informed by the volitional } \\
\text { constructs of the Health Action Process Approach to } \\
\text { building a robust and realistic action plan to avoid } \\
\text { drink driving in the future, by specifying a range of } \\
\text { options and building/maintaining confidence to use } \\
\text { future plans (maintenance self-efficacy). } \\
\text { Components of the Transtheoretical Model (TTM) } \\
\text { approach are used in the form of decisional balance } \\
\text { with personalised feedback to motivate change in } \\
\text { drink driving behaviour. The Cognitive Behavioural } \\
\text { Therapy (CBT) Model approach is also introduced to } \\
\text { allow offenders to consider how thoughts may }\end{array}$ & $\begin{array}{l}\text { Action planning. } \\
\text { Coping planning. } \\
\text { Relapse prevention. } \\
\text { Maintenance self- } \\
\text { efficacy. } \\
\text { Barrier } \\
\text { identification/ } \\
\text { problem solving. } \\
\text { Planning social } \\
\text { support. }\end{array}$ \\
\hline
\end{tabular}




\begin{tabular}{|c|c|c|}
\hline & $\begin{array}{l}\text { influence behaviour when considering decisions } \\
\text { around driving after drinking. Social supports are } \\
\text { also identified, and social contexts are explored. }\end{array}$ & \\
\hline $\begin{array}{l}\text { Module 5: } \\
\text { Your alcohol } \\
\text { use }\end{array}$ & $\begin{array}{l}\text { Drink drivers are significantly more likely to exhibit } \\
\text { alcohol related problems and risky alcohol use. }\end{array}$ & $\begin{array}{l}\text { Social } \\
\text { comparison/AUDIT } \\
\text { screening } \\
\text { normative } \\
\text { (national) data } \\
\text { comparison. } \\
\text { Goal setting. } \\
\text { Motivational } \\
\text { interviewing/stages } \\
\text { of change. } \\
\text { Cognitive } \\
\text { behavioural } \\
\text { techniques. } \\
\text { Referral to services } \\
\text { if high risk. }\end{array}$ \\
\hline $\begin{array}{l}\text { Module 6: } \\
\text { Have your say }\end{array}$ & $\begin{array}{l}\text { Allows for in-built evaluation of program } \\
\text { components in real time (e.g. 'the webpages were } \\
\text { easy to navigate', 'I found the content to be visually } \\
\text { engaging'). }\end{array}$ & $\begin{array}{l}\text { Evaluation } \\
\text { (enabling research } \\
\text { and updates). }\end{array}$ \\
\hline $\begin{array}{l}\text { Drink tracker } \\
\text { web app }\end{array}$ & $\begin{array}{l}\text { Brief online interventions are more effective when } \\
\text { there is an ongoing component. The tracker enables } \\
\text { users to self-regulate by tracking drinks, viewing } \\
\text { graphic representations of drinking, as well as } \\
\text { enabling them to refer to and modify their plan built } \\
\text { during participation in Steering Clear. }\end{array}$ & $\begin{array}{l}\text { Self-monitoring of } \\
\text { behavioural } \\
\text { outcomes (drink } \\
\text { driving and alcohol } \\
\text { use). }\end{array}$ \\
\hline
\end{tabular}




\section{Compliance with ethical standards}

This study was funded with a proof-of-concept grant by QUTbluebox awarded to the research team and led by Barry Watson. Hollie Wilson declares that she has no conflicts of interest. Gavan Palk declares that he has no conflicts of interest. Mary Sheehan declares that she has no conflicts of interest. Darren Wishart declares that he has no conflicts of interest. Barry Watson declares that he has no conflicts of interest.

All procedures performed in studies involving human participants were in accordance with the ethical standards of the institutional and/or national committee and with the 1964 Helsinki declaration and its later amendments or comparable NHMRC ethical standards. Informed consent was obtained from all individual participants in this study.

\section{References}

1. Compton RP, Blomberg RD, Moskowitz H, Burns M, Peck RC \& Fiorentino D. Crash rate of alcohol impaired driving. Proceedings of the Sixteenth International Conference on Alcohol, Drugs and Traffic Safety ICADTS, Montreal, 2002.

2. Sheehan M. A 0.05 BAC limit in the United States : an important challenge for policy, health and safety. Addiction. 2014;109(6)875.

3. Australian Transport Council (ATC). National road safety strategy 2011-2020.

Available from:

http://www.infrastructure.gove.au/roads/safety/national road safety strategy/files/NRSS 20112020 15Aug11.pdf

4. Department of Transport and Main Roads. Queensland drink driving discussion paper. Queensland, Australia. 2010.

5. Stats IW. Internet Usage Statistics: The internet big picture, world internet users and 2015 population stats: Miniwatts Marketing Group; 2015 [28/08/2015]. Available from: http://www.internetworldstats.com/stats.htm

6. Australian Mobile Phone Lifestyle Index. Australia: 2014

7. Nielsen Mobile Ratings. The mobile story. Australia: 2015.

8. Patient adoption of mHealth: Use, evidence and remaining barriers to mainstream acceptance. February 2016. Parsippany, NJ: IMS Institute for Healthcare Informatics.

9. Rooke S, Thorsteinsson E, Karpin A, Copeland J \& Allsop D. Computer-delivered interventions for alcohol and tobacco use: a meta-analysis. Addiction. 2010;105(8):13811390.

10. Portnoy DB, Scott-Sheldon LA, Johnson BT, Carey MP. Computer-delivered interventions for health promotion and behavioral risk reduction: a meta-analysis of 75 randomized controlled trials, 1988-2007. Preventive medicine. 2008;47(1):3-16.

11. Riper H, Spek V, Boon B, Conijn B, Kramer J, Martin-Abello K, et al. Effectiveness of Eself-help interventions for curbing adult problem drinking: a meta-analysis. Journal of medical Internet research. 2011;13(2):e42.

12. White A, Kavanagh D, Stallman H, Klein B, Kay-Lambkin F, Proudfoot J, et al. Online alcohol interventions: a systematic review. Journal of medical Internet research.

2010;12(5):e62.

13. Webb TL, Joseph J, Yardley L, Michie S. Using the internet to promote health behavior change: a systematic review and meta-analysis of the impact of theoretical basis, 
use of behavior change techniques, and mode of delivery on efficacy. Journal of medical Internet research. 2010;12(1):e4.

14. Mullen J, Ryan S, Mathias C, Dougherty D. Feasibility of a computer-assisted alcohol screening, brief intervention and referral to treatment program for DWI offenders.

Addiction Science \& Clinical Practice. 2015;10(1):25

15. Osilla KC, Paddock SM, Leininger TJ, D'Amico EJ, Ewing BA, Watkins KE. A pilot study comparing in-person and web-based motivational interviewing among adults with a firsttime DUI offense. Addict Sci Clin Pract. 2015;10:18.

16. Schwarzer R, Lippke S \& Luszczynska A. Mechanisms of health behavior change in persons with chronic illness or disability: The health action process approach (HAPA). Rehabilitation Psychology. 2011;65:161-170.

17. Carey K, Scott-Sheldon LA, Elliott J, Bolles JR \& Carey MP. Computer-delivered interventions to reduce college student drinking: A meta-analysis. Addiction.

2009;104:1807-1819.

18. Khadjesari Z, Murray E, Hewitt, C, Hartley Z \& Godfrey C. Can stand-alone computerbased interventions reduce alcohol consumption? A systematic review. Addiction. 2011;106(2):267-282.

19. Apodaca TR \& Miller WR. A meta-analysis of the effectiveness of bibliotherapy for alcohol problems. Journal of Clinical Psychology. 2003;59(3):289-304.

20. Alcohol-Use Disorders: Preventing the Development of Hazardous and Harmful Drinking. London: National Institute for Health and Clinical Excellence (NICE), 2010.

21. Cunningham RM, Harrison SR, McKay MP, Mello MJ, Sochor M, Shandro JR, et al. National survey of emergency department alcohol screening and intervention practices. Annals of Emergency Medicine. 2010;55(6):556-62.

22. Difulvio GT, Linowski SA, Mazziotti JS, Puleo E. Effectiveness of the Brief Alcohol and Screening Intervention for College Students (BASICS) program with a mandated population. Journal of American College Health : J of ACH. 2012;60(4):269-80.

23. Kaner E. NICE work if you can get it: Development of national guidance incorporating screening and brief intervention to prevent hazardous and harmful drinking in England. Drug and alcohol review. 2010;29(6):589-95.

24. Lock CA, Kaner EF. Implementation of brief alcohol interventions by nurses in primary care: do non-clinical factors influence practice? Family practice. 2004;21(3):270-5. 25. O'Donnell A, Anderson P, Newbury-Birch D, Schulte B, Schmidt C, Reimer J, et al. The impact of brief alcohol interventions in primary healthcare: a systematic review of reviews. Alcohol and Alcoholism. 2014;49(1):66-78.

26. Heather N. Brief interventions. In: N. H., Stockwell T, editors. The essential handbook of treatment and prevention of alcohol problems. Chichester, England: John Wiley \& Sons; 2004. pp. 117-38.

27. Babor TF, Biddle-Higgins JC, Saunders JB, Monteiro MG. The alcohol use disorders identification test: Guidelines for use in primary health care. Geneva, Switzerland: World Health Organization, 2001.

28. Hettema J, Steele J, Miller WR. Motivational interviewing. Annual review of clinical psychology. 2005;1:91-111.

29. Short C, Rebar A, Plotnikoff RC, Vandelanotte C. Designing engaging online behaviour change interventions : a proposed model of user engagement. The European Health Psychologist. 17(1):32-8. 
30. Fuller T, Kroese F. Tailor made for Health Psychology: Issues in design and effectiveness of internet interventions. The European Health Psychologist. 2015;17(1):2-4. 31. Gerhard M, Moore D \& Hobbs D. Embodiment and copresence in collaborative interfaces. International Journal of Human-Computer Studies. 2004;61(4):453-480.

32. Bailey F \& Moar M. The Vertex Project: Children Creating and Populating 3D Virtual Worlds. The International journal of Art and Design Education. 2001;20(1);19-30.

33. Falloon G. Using avatars and virtual environments in learning: What do they have to offer? British Journal of Educational Technology. 2010;41(1):108-22.

34. National statement of ethical conduct in human research. Australian Vicechancellors' Committee, National Health and Medical Research Council (Australia), \& Australian Research Council. Canberra. 2007.

35. Kreuter M \& Wray R. Tailored and Targeted Health Communication: Strategies for Enhancing Information Relevance. American Journal of Health Behavior. 2007;37(3):52275232.

36. Wilson $\mathrm{H}$, Sheehan MC, Palk GR. Who are the real "first offenders"? International Council on Alcohol, Drugs and Traffic Safety Conference (T2010); Oslo, Norway; 2010.

37. Prochaska JO, Velicer WF. The Transtheoretical model of health behavior change. American Journal of Health Promotion. 1997;12:38-48. 